* Doutor em Direito Público pela Universidade do Vale do Rio dos Sinos

Professor Adjunto I do Departamento de Direito da Universidade Federal de Santa Maria E-mail: ferdhoffa@ yahoo.com.br

\section{NORMATIVIDADE IMPERIAL, LAW SHO- PPING E EMPRESAS TRANSNACIONAIS: COMO FICAM OS DIREITOS HUMANOS!?}

\author{
IMPERIAL NORMATIVITY, LAW SHOPPING AND \\ TRANSNATIONAL COMPANIES: HOW ARE HUMAN \\ RIGHTS!?
}

Fernando Hoffmam *

Como citar: HOFFMAM, Fernando. Normatividade imperial, law shopping e empresas transnacionais: como ficam os direitos humanos!?. Scientia luris, Londrina, v. 25 , n. 3, p. 25-48, nov. 2021. DOI: $10.5433 / 21788189.2021 v 25 n 3 p 25$. ISSN: $2178-8189$.

Resumo: O presente trabalho se propõe analisar e compreender a relação entre a constituição de uma nova normatividade "imperial", a ação das empresas transnacionais e a utilização sistemática do law shopping por essas empresas. A partir da construção de uma nova normatividade que se origina a partir das normas técnicas e de gestão (standards e indicadores) que passam a instituir novas ordens normativas para além do Estado e da normatividade estatal (constitucional), procura-se entender como as empresas transnacionais se movimento nesse cenário na busca pela normatividade mais vantajosa para o desenvolvimento de suas atividades. Assim, procura-se desvelar o surgimento de novos atores privados e de novos centros de produção e aplicação de normas, bem como, de uma pluralidade normativa, desvelando as suas características ocultas. Dessa forma, se objetiva compreender o processo de interação dessas normatividades com a normatividade constitucional (estatal), e a utilização do law shopping como possibilidade de burlar os sistemas jurídicos nacionais e internacionais, ou, de minimizar os seus efeitos, relegando ao Direito um papel secundário. Nesse caminho, qual seria o papel do constitucionalismo e do Direito para a proteção, garantia e concretização dos direitos humanos face ao "Império", às empresas transnacionais e à prática do law shopping no sentido de fragilizar o Direito e violar os direitos humanos?

Palavras-chave: Direito humanos. Empresas transnacionais. "Império". Law Shopping. Pluralidade normativa.

Abstract: The present work aims to analyze and understand the relationship between the constitution of a new "imperial" 
normativity, the action of transnational companies and the systematic use of law shopping by these companies. From the construction of a new normativity that originates from the technical and management norms (standards and indicators), that start to institute new normative orders in addition to the State and state (constitutional) normativity, we seek to understand how transnational companies move in this scenario in the search for the most advantageous normativity for the development of their activities. Thus, it seeks to reveal the emergence of new private actors and new centers for the production and application of standards, as well as a plurality of regulations, revealing their hidden characteristics. Thus, the objective is to understand the process of interaction between these norms and constitutional (state) norms, and the use of law shopping as a possibility to circumvent national and international legal systems, or to minimize their effects, relegating to law a secondary role. In this way, what would be the role of constitutionalism and law for the protection, guarantee and realization of human rights in the face of the "Empire", transnational companies and the practice of law shopping in order to weaken the law and violate human rights?

Keywords: Human rights. Transnational companies. "Empire". Law Shopping. Normative plurality. 


\section{INTRODUÇÃO}

O Direito na atualidade está inserido em um panorama de transformações que afetam, para além do próprio direito, o seu lugar privilegiado de produção e aplicação, qual seja, o Estado. Nesse sentido, é evidente a perda do monopólio estatal de produção e aplicação do direito face a outros centros de poder que se proliferam na ordem nacional e internacional, agindo globalmente no que tange à produção e aplicação normativas e fazendo com que surja o questionamento pelo lugar do Estado e do constitucionalismo nesse cenário. Porquanto, se o paradigma estatal e o constitucionalismo que o acompanha perdem espaço, e isso é inegável, essa perda de espaço se dá diretamente pelo surgimento de um novo paradigma de soberania denominado de "Império". A constituição do "Império" no tocante ao Direito e ao Estado implica no "surgimento" de novos atores (as empresas transnacionais) e de uma nova normatividade "imperial" (normas técnicas e de gestão), gerando uma descentralização em relação à produção e aplicação do Direito, e, ao mesmo tempo, uma centralização em um novo centro de biopoder: o "Império" (Parte 1).

Dessemodo, torna-se importante compreender oprocesso de interação entre a normatividade jurídica e a nova normatividade "imperial", desvelando se o seu acontecimento acorre sob a forma do diálogo ou da concorrência. Nesse cenário em que proliferam normatividades e atores, e em que o paradigma econômico neoliberal se consolida, as interações entre variadas normatividades se dá pelo prisma da concorrência normativa, em um verdadeiro comercio de normas e de sistemas jurídicos, que são escolhidos por suas fragilidades, e não por suas capacidades. (Parte 2).

Nesse cenário, um dos principais mecanismos utilizados pelos atores privados, sobretudo pelas empresas transnacionais pelo viés de escolher qual o sistema jurídico e qual a normatividade mais benéfica ao desenvolvimento de suas atividades, visando o maior lucro possível, é o law shopping. A partir das práticas de law shopping se institucionaliza um contexto de competitividade entre ordens jurídicas, normatividades, e Estados, em uma corrida pelo ordenamento jurídico mais atrativo para as empresas transnacionais; contudo, quantos mais atrativa for a ordem jurídica, mais vulnerável ela será, estando aí a importância do constitucionalismo e dos direitos humanos como parâmetro para essas interações e escolhas normativas (Parte 3).

Para tanto, utiliza-se como referencial metodológico e teórico-analítico o materialismo histórico no viés ${ }^{1}$ de Antonio Negri. Aqui, certamente, cabem algumas explicações: a construção teórica de Antonio Negri se desenvolve no terreno do marxismo. No entanto, a corrente do pensamento marxista representada por Negri busca uma atualização do marxismo no sentido de situá-lo frente às dinâmicas contemporâneas, mas sem se afastar dos conceitos fundamentais do materialismo histórico marxista, que são: a) a tendência histórica, b) a abstração real, c) o antagonismo e d) a constituição da subjetividade. Neste sentido, o método de Negri considera o antagonismo entre uma subjetividade criativa e uma subjetividade constituída pelo capital. É neste sentido que se estabelecem novas categorias de análise que permitem compreender o papel do

1 Aqui é importante referir que para a construção do referencial metodológico e teórico-analítico que aqui o presente trabalho, além de se levar em conta a obra de Antonio Negri, também se toma por base a leitura empreendida por Márcio de Souza Bernardes em: (BERNARDES, 2017). 
Estado e do Constitucionalismo nesse cenário, compreendendo o fenômeno da produção normativa estatal a partir dessas categorias, em antagonismo às normatividades "imperiais", e como forma de proteção dos direitos humanos face à ação das empresas transnacionais e a práticas "imperiais" como o law shopping. É neste sentido que se estabelece nosso marco teórico e metodológico, e que se define a forma como trabalhar-se-á, nesse artigo, o materialismo histórico. Assim, a utilização desse método permeia todo o desenvolvimento do trabalho realizado, que tem como eixo central as lutas presentes na modernidade e na pós- modernidade entre as forças do capital e as forças de resistência.

\section{O DIREITO ENTRE CONSTITUCIONALISMO E NORMATIVIDADE "IMPERIAL"}

De pronto, é necessário considerar o Estado como se apresenta no presente artigo a partir do seu modelo moderno, ou seja, inserido em uma historicidade própria, sendo localizado geograficamente, e tendo uma temporalidade que determina uma dada compreensão das suas formas e transformações (BOLZAN DE MORAIS; HOFFMAM, 2015). Desse modo, se inicia o presente texto quando se fala em monopólio estatal, de uma centralidade na produção e aplicação do Direito, bem como da positivação, garantia e concretização dos direitos que surge a partir do modelo absolutista de Estado, e que passa por inúmeras transformações até chegar à sua roupagem e Estado Democrático de Direito, sobre o qual efetivamente o presente trabalho acabará se ocupando.

Nessa perspectiva, o Estado, nas suas formas modernas, desde o modelo absolutista, passando pelo seu viés Liberal e chegando-se ao Estado Social, mantém uma centralidade que é inegável e, no mais das vezes, justamente por reunir o monopólio da força no que tange à sua construção e utilização, incontestável. As formas estatais modernas, embora diferenciem-se entre si, mantém-se adstritas à um núcleo central e a características que as marcam e definem².

Essas características, sem dúvida alguma, podem ser apontadas como a relação do poder estatal com a noção de soberania, e também estão ligadas à definição de um determinado povo que é o que conforma humanamente determinado Estado, e certamente informa o pertencimento do Estado a um determinado lugar, ou seja: a estatalidade tem necessariamente um território e consequentemente é marcado por fronteiras. (BOLZAN DE MORAIS, 2011). É claro que, a partir desse núcleo central, desdobram-se outras características que marcam o paradigma estatal em todas as suas formulações, como o exercício soberano da jurisdição, e, logo, do poder em relação aos seus cidadãos, a definição soberana de suas políticas internas e externas, as prerrogativas atinentes à sua atuação na arena internacional, a formação de uma Constituição própria, entre

\footnotetext{
2 A título de esclarecimento, é importante deixar claro que não se pretende no presente artigo abordar específica e detidamente cada paradigma estatal e suas características, mas sim, apontar as características gerais, e, ainda assim, não de forma exaustiva, à todas as formas estatais desde a modernidade, ou seja, perceber um núcleo comum que permeia o Estado moderno em todas as suas formações, apontando especificamente as mais importantes no que tange ao artigo. Para um maior aprofundamento sobre essas questões, ver: (BOLZAN DE MORAIS, 2005; STRECK; BOLZAN DE MORAIS, 2019).
} 
outras tantas igualmente importantes.

Veja-se que se consolida um ponto extremamente importante para o presente texto, que é justamente a importância da Constituição e conjuntamente de um constitucionalismo que se transmuta e passa a ter uma importância vital para a garantia e concretização dos direitos dos cidadãos que habitam os textos constitucionais. É nesse caminho que, sobretudo após a Segunda Guerra Mundial, o constitucionalismo garantidor de direitos que revive após o caos da violação sistemática e massiva dos direitos humano-fundamentais mais caros ao ser humano perpetrada pela maquinaria nazi-fascista se internacionaliza e passa a conformar todo um arcabouço jurídico internacional de direitos e de humanos; passam a ser da humanidade. (BOLZAN DE MORAIS; SALDANHA; VIEIRA, 2013).

Estado, Direito e constitucionalismo chegam a um ponto em que não se pode mais arredar da normatividade da Constituição, bem como não se pode mais fazer concessões no que tange aos direitos humanos, seja na perspectiva interna (nacional), seja na esfera externa (internacional), pois os direitos humano-fundamentais, garantidos constitucionalmente, são também garantidos para além dos limites do Estado e do constitucionalismo que o acompanha. A soberania estatal é também uma soberania constitucional, e os direitos humano-fundamentais devem ser garantidos e concretizados consolidando essa caminhada do nacional ao internacional, e de uma apreensão além-fronteiras da normatividade constitucional no que tange especificamente a esses direitos.

Porquanto, se o movimento de internacionalização do direito e do constitucionalismo corrobora para uma ampliação conteudística e protetiva no que toca aos direitos humanos, já que essa internacionalização do Direito se dá sobretudo pela ótica dos direitos humanos, ela também gera uma abertura paradigmática da estatalidade.

Há uma abertura paradigmática que atinge a estatalidade e a juridicidade, e provoca uma permeabilidade entre nacional e internacional que configura uma nova forma de organização das instituições clássicas que surgem com o paradigma estatal. (BOLZAN DE MORAIS; HOFFMAM, 2015). O constitucionalismo que esteve durante toda a sua história até aqui ligado ao Estado, descentra-se desse locus privilegiado de poder, pois é atingido em cheio pelo fenômeno da globalização, passando a lidar com outras perspectivas e centros de poder quer perpassam a estatalidade e vão muito além da mesma.

Nessa conjuntura, o estatalismo passa por uma série de crises, que em parte também é uma crise do constitucionalismo ligado à forma Estado. Se há uma crise conceitual, como já referido, há também uma crise que é constitucional e que permeia os caminhos apontados pelo Estado na atualidade na direção da garantia e concretização de direitos, mas, ao mesmo tempo, muitas vezes no caminho inverso da relativização desses direitos decorrente da relativização da própria Constituição e da figura estatal. (BOLZAN DE MORAIS, 2011).

Esses tensionamentos importam, entre outras questões, na perda do monopólio estatal no que tange à produção e aplicação do Direito, o que pode, sem dúvida alguma, apontar para uma direção benéfica ligada ao pluralismo social, ao reconhecimento das diferenças, de novos direitos ligados à novos sujeitos, ao reconhecimento dos movimentos sociais e das lutas por direitos que 
deles tomam forma, mas também pode partir de uma agenda negativa que se relaciona com questões que são postas e pensadas ao arrepio do Estado, do Direito, do constitucionalismo, e nesse bojo, dos direitos humano-fundamentais.

Essa movimentação contemporânea do Estado e do constitucionalismo podem significar a abertura, construção, invenção ou imposição de novos espaços normativos, o que pode beneficiar a constituição de espaços normativos cosmopolitas - ainda que sob a égide de um novo cosmopolitismo ${ }^{3}$ - mas, também, pode gerar locus de poder e normatividade que não se interessam ou se conectam com desideratos cosmopolitas, democráticos, e de proteção, garantia e concretização dos direitos humanos. (BOLZAN DE MORAIS; HOFFMAM, 2015). Tanto emergem convergências nas tradições jurídicas que se conectam, quanto se percebe uma homogeneização jurídico-cultural, sob o risco de um imperialismo de tradições jurídicas hegemônicas ditadas pelo predomínio econômico que se converte em político, jurídico e cultural através da instituição do "Império" enquanto novo paradigma de soberania. Há, assim, pode-se dizer figurativamente, novo(issimo)s constitucionalismos - como o nomeado "Novo" constitucionalismo LatinoAmericano - ao lado de velhos constitucionalismos, bem como da ausência, parcial ou total do mesmo constitucionalimo.

Nesse momento, se institui uma nova normatividade que, para o presente artigo, nasce do paradigma do "Império", e está inserida na lógica "imperial" de sobreposição ao e utilização do Estado como mais uma estrutura "imperial" de poder. O "Império" produz uma normatividade que se dá ao arrepio do Estado e da ordem democrática, bem como não se importa no mais das vezes com as exigências dos direitos humanos, seja em nível nacional ou internacional.

A partir desse momento, para o presente texto passa o Direito a lidar com ordens normativas distintas, oriundas de lugares próprios de produção do Direito, ligadas a atores diversos, e buscando variados interesses que não os da ordem democrática e dos direitos humanos. Quando se fala aqui em diferentes normatividades ou ordens normativas, desde esse momento fala-se em uma normatividade, em normas construídas legislativamente dentro do jogo democrático, oriundas do Estado e necessariamente compatíveis com a constitucionalidade e com os direitos garantidos constitucionalmente; essas normas para esse trabalho serão denominadas de normas jurídicas. No entanto, há uma normatividade procedente de outros atores e produzida em outros lugares, coadunando novos desideratos, novos meios de produção, e novos órgãos de aplicação do Direito, que não mais exclusivamente os pertinentes à estatalidade e ao constitucionalismo. A essas normas se dará o nome de normas de gestão (standards e indicadores) conformando uma normatividade “imperial”, e é o que se passa a tratar.

Nessa caminhada, é imprescindível, já de imediato, determinar conceitualmente o que é o "Império", e já, antes de qualquer coisa, uma advertência se faz necessária: o "Império" é um conceito e não uma metáfora relacionada aos tempos imperiais, ou seja, à experiência romana, chinesa, americana - aqui se fala em continente americano - anteriores. Partindo daí o "Império" se caracteriza pela ausência de fronteiras, e, assim, estende o seu poder e a sua normatividade

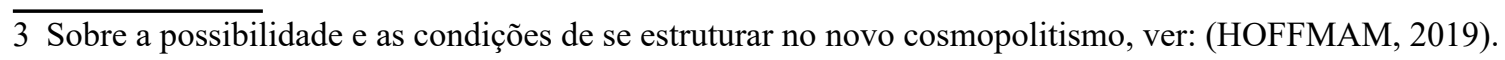


sobre todo o mundo civilizado abrangendo a totalidade do espaço; num segundo momento, é importante demarcar que o "Império" não nasce de processos de conquista, mas sim como uma ordem de coisas que se coloca naturalmente, e perenemente suspendendo a história e fundando uma temporalidade própria. Também é importante deixar claro que o "Império" projeta o seu poder por toda a ordem social, e não apenas pela ordem política e jurídica como espaços típicos do exercício da soberania, por isso se coloca como uma forma de biopoder e biopoliticamente controla a própria vida dos indivíduos, até mesmo formando novas subjetividades. E, paradoxalmente, embora se estruture e movimente a partir de um estado de guerra global, o conceito de "Império" é sempre dedicado a paz, no entanto, uma paz do sistema - paz "imperial”. (HARDT; NEGRI, 2002).

Dessa forma, o conceito de "Império" é um conceito global que emana o seu poder de um único centro, mostrando-se como um poder unitário responsável por manter a paz social e produzir os seus valores éticos. Para alcançar esse desiderato lhe é dada a força necessária e o poder do exercício da coerção, configurando-se um biopoder capaz de buscar a manutenção da paz controlando as guerras às quais produz. (HARDT; NEGRI, 2002). Com efeito:

O novo paradigma é ao mesmo tempo estrutura e hierarquia, construção centralizada de normas e produção de legitimidade de grande alcance, espalhada sobre o espaço mundial. É configurado ab initio como dinâmica e flexível estrutura sistêmica, articulada horizontalmente [...]. [...] Alguns chamam de "governança sem governo" para indicar a lógica estrutural, às vezes imperceptível mas sempre e cada vez mais efetiva, que move todos os atores dentro da ordem global. (HARDT; NEGRI, 2002, p. 31).

Nesse sentido, há uma nova autoridade central que organiza e estrutura um sistema de práticas, mecanismos e normatividades que partem dela e chegam nela, ou seja, o paradigma "imperial" é ponto de partida e de chegada de toda a normatividade, e de todas as práticas que conduzem a política “imperial”. Nesse viés, Hardt e Negri (2002) questionam se o termo jurídico ou Direito ainda deve ser utilizado no atual contexto "imperial", e respondem no sentido de que as normas supranacionais acabam por adentrar e se sobrepor à ordem normativa adstrita ao Estadonação, ou seja, o chamado Direito transnacional aberto e flexível se sobrepõe ao Estado e ao constitucionalismo deixando-os em segundo plano, mas não os eliminando.

Traça-se uma paisagem jurídico-normativa imprecisa, pois atacada pela ordem "imperial" e sua normatividade descentralizada, e, principalmente, despreocupada com a estatalidade, com a ordem constitucional, e com os direitos humanos oriundos dessas instituições. A nova normatividade "imperial" inaugura uma crise da racionalidade moderna e das instâncias de produção e aplicação do Direito, o que implica num desgaste e perda de importância da normatividade jurídica frente à normatividade “imperial”. (SALDANHA; MELLO; LIMBERGER, 2016).

Ugo Mattei $(2003)^{4}$, nessa linha, embora fale de um processo de americanização do direito, o qual não se coaduna com o intento desse artigo, acerta ao proclamar que a normatividade

4 Tradução livre do autor: "Imperial law is shaped by a spectacular process of exaggeration, aimed at building consent for the purpose of hegemonic domination". 
imperial é dominante no sistema jurídico mundial, bem como que ela é produzida no interesse do capital e por uma infinidade de atores privados, que por óbvio são responsáveis por um déficit de democracia dessa nova normatividade. "A lei imperial é moldada por um espetacular processo de exagero, visando a construção de consentimento com a finalidade de dominação hegemônica".

O novo paradigma imperial de soberania faz com que essa nova normatividade permeie indistintamente as normatividades estatais utilizando-as quando necessário, mas também as descartando sempre que afrontarem esse novo paradigma. Nesse sentido, é bastante claro Jose Luis Bolzan de Morais ao afirmar que o Estado de Direito na atualidade se vê impactado por uma nova forma de conhecimento e de produção normativa, que invade a institucionalidade e toma de assalto os ambientes de produção regulamentar, modificando toda a fenomenologia que conduz essa produção. Como propõe o autor, substitui-se a normatividade jurídica alicerçada na política, e democraticamente construída, por uma normatividade privada concentrada no poder da razão matemática. (BOLZAN DE MORAIS, 2018a). É o que se pode chamar com Dardot e Laval (2016) de "nova razão do mundo", ou seja, uma razão matemática, mercadológica e financeirizada que aporta uma nova razão governamental, constituindo um novo aparelho de Estado que acaba por se colocar à serviço do novo paradigma de soberania.

É evidente que o paradigma "imperial" de soberania só consegue tomar forma a partir de uma "grande virada mediante a implantação geral de uma nova lógica normativa, capaz de incorporar e reorientar duradouramente políticas e comportamentos numa nova direção" (DARDOT; LAVAL, 2016, p. 190), constituindo-se uma nova forma de estatalidade, uma nova normatividade e um novo constitucionalismo que se colocam à serviço do "Império" e de sua força normativa descentralizada, mas, ao mesmo tempo, rígida e extremamente coercitiva.

Dialogando, as teorias de Hardt e Negri (2002) com Frydman (2018) pode-se chegar a uma definição do que é essa nova normatividade "imperial", ou seja, de que tipo de normas se está a falar. A partir das ideias de Frydman (2018), propõe-se em meio ao novo paradigma de soberania uma normatividade que busca padronizar tanto as coisas, e aqui se está falando sobre o domínio das normas técnicas, quanto busca padronizar a ação humana, quando falamos das normas de gestão.

As normas técnicas tendem à padronização das coisas, dos processos e procedimentos, das exigências de qualidade dos produtos e materiais, são normas que buscam uma normalização das condutas técnico-produtivas na busca por uma maior qualidade diretamente ligada à padronização. Essas normas antes internas às fabricas, às empresas, migra para além delas e acaba por constituir normas gerais de setores e associações profissionais. São exemplos dessas normas, as normas ISO que geram uma padronização global de processos e condutas alinhados com demandas de padronização que estão para além da estatalidade. (FRYDMAN, 2018).

"O velho Rule of Law vai sendo sucedido por um modelo de governança no qual a sustentação dos atos de poder é conferida pelo respeito à standars e indicadores administrativos 
e não mais aos conteúdos tradicionais do Estado (Liberal) de Direito". (BOLZAN DE MORAIS, 2018b, p. 876-903). É o que se pode chamar de governança por números, ou seja, uma forma de governo centrada na análise pelo cálculo, na quantificação dos resultados e na programação dos comportamentos dos sujeitos de acordo com padrões normativos apontados por essa mesma governança. (SUPIOT, 2014).

No início do século XX, os Estados começam a organizar e criar institutos nacionais de normalização técnica; o primeiro país a tomar essa atitude é a Holanda, seguida num primeiro momento pela Alemanha em 1917 e pelos Estados Unidos em 1918. Mais tarde, criam também seus organismos estatais de normalização a França, em 1926, com a Bélgica criando o seu órgão em 1959. Veja-se que, num primeiro momento, esse movimento se dá em nível estatal (nacional), mas na atualidade essa é uma demanda internacional (global) que necessita de normas técnicas coerentes e obedecidas em todo o globo terrestre, padronizando processos, procedimentos, exigências por qualidade, utilização de materiais, etc. (FRYDMAN, 2018).

Nesse plano, ganham também espaço as normas de gestão e a construção de uma nova administração voltada para a busca por eficiência e por uma qualidade que não é mais substantiva, mas sim quantitativa. As normas de gestão passam a habitar as instituições tipicamente estatais em uma ode à eficiência, colocando em segundo plano a efetividade das medidas tomadas em relação aos sujeitos, aos cidadãos. Como deixa claro Frydman (2018), qualidade e quantidade andam juntas nesses novos tempos, pois a qualidade é medida pelo emprego da cifra, ou seja, o que aponta a qualidade da gestão, tanto quanto o que aponta a qualidade técnica são indicadores, dados, cifras, que quantificam a efetividade 5 .

Nessa trilha, “se o 'dado' é apresentado como um componente do real (ainda que seja um produto de fabricação de um indicador definido), o objetivo a alcançar é uma norma, a norma que orienta o comportamento em direção ao fim a alcançar" (FRYDMAN, 2018, p. 49), esse fim a alcançar na lógica "imperial” engloba a eficiência e a produtividade como dados, mas também engloba os valores éticos que devem traçar esse caminho rumo ao fim a alcançar. Há uma dupla normatividade técnica e ética, que reveste a norma "imperial" enquanto norma técnica ou de gestão para além de sua função pragmática, de uma eticidade que obedece à ética do sistema, à ética "imperial", sendo uma ética também técnica, numérica, quantitativa e, sobretudo privada.

A standartização do Direito e de sua normatividade faz com o que o constitucionalismo e a juridicidade soçobrem frente ao aparato global de poder "imperial". O biopoder "imperial" estende seus mecanismos de controle sobre o Direito e controla a produção normativa à nível estatal, produzindo um descompasso entre os desideratos do Estado e dos direitos humanos

\footnotetext{
5 Nesse ponto é importante mencionar que na atualidade se faz por demais presente na análise estatística por dados e cifras a presença das novas tecnologias da informação e comunicação (TICs). Nesse sentido, a utilização da análise algorítmica no que tange à dados e cifras é um fator de potencialização da quantificação que orienta os movimentos das instituições públicas e privadas na atualidade. Os algoritmos nesse sentido também se mostram extremamente normativos, mas, também, tem a sua normatividade ocultada, bem como, tem os seus verdadeiros intentos escamoteados por estratégias discursivas de neutralidade. No entanto, os números não são neutros, e muito menos os algoritmos programados especificamente para a partir de análises preditivas gerar esses números. Sem sombra de dúvidas a nova normatividade "imperial" composta pelas normas técnicas e de gestão pode ser caracterizada cada vez mais como uma normatividade algorítmica, orientada por uma razão algorítmica programada sob os interesses do "Império". (BOLZAN DE MORAIS, 2018b, p. 876-903).
} 
e as intenções dos agentes privados e das demais institucionalidades "imperiais", que reúne até mesmo outros Estados que, como competidores na arena global, se sobrepõem aos direitos humanos e a outras estatalidades.

"Da mesma forma que uma constituição na ordem jurídica, a informação estatística é essencialmente normativa e serve para construir um espaço público. Mas, diferentemente de uma constituição, sua normatividade é ocultada" (SUPIOT, 2014, p. 74), ou seja, o "Império" comanda sem comandar, ou exerce o seu poder sem que pareça isso um exercício de poder, pois a normatividade "imperial" não faz aparecer as suas intenções, muito menos passa por controles democráticos ou debates públicos, ela apenas é gerada a partir do próprio "Império" para exercer o seu biopoder invisível e guiar o mundo sem saber que está sendo guiado.

Por isso o "Império" aparece como uma ordem natural; constitui-se a priori porque isso era inafastável, inevitável, sua constituição é dada naturalmente como um novo paradigma soberano que se estende inadvertidamente sobre todo o mundo e coloca toda a institucionalidade até ali existente sobre os braços das suas estruturas e mecanismos de biopoder, controle e vigilância. (HARDT; NEGRI, 2002). Porquanto, em que pese, todas as institucionalidades fiquem sob o seu comando e possam se movimentar nessa lógica, nesse espaço-tempo suspenso, determinados Estados e sobretudo, os atores privados se movimentam com maior êxito e comandam os rumos que a imensa maioria dos atores estatais ou não devem seguir.

Dessa forma, mesmo que a normatividade "imperial" se produza a partir de um biopoder central forte e denso, os atores privados atuam com liberdade e facilidade por suas estruturas, seja de produção quanto de aplicação das normas. É evidente que as normas técnicas e de gestão nascem, sobretudo, da esfera privada e de atores que habitam o ambiente "imperial”, bem como o ambiente estatal, mas que atuam para além das normas estatais e constitucionais.

Assim, as variadas normatividades que se colocam no espaço-tempo "imperial" passam necessariamente a relacionar-se e a criar vínculos no que tange à sua produção e aplicação. No entanto, o que deve ser questionado é como se dá essa relação, e no tocante às novas normatividades "imperiais", como elas atingem a Constituição enquanto norma e o constitucionalismo enquanto garante dos direitos humano-fundamentais. Na sequência é disso que se trata.

\section{O "PRINCÍPIO" DA CONCORRÊNCIA COMO NOVA "RAZÃO NORMATIVA"}

Nesse momento torna-se necessário e imprescindível que se compreenda como se relacionam as variadas normatividades existentes na contemporaneidade, ou seja, como a partir da instituição do paradigma "imperial" e das modificações passadas pelo Estado, tanto em suas funções quanto em sua estrutura, se dá a interação entre a nova normatividade "imperial" através das normas técnicas e de gestão e a normatividade estatal-constitucional através do Direito produzido legislativamente dentro das instituições democráticas.

De maneira cristalina essa interação ocorre e não pode ser negada, porquanto é preciso 
entender se esse entrecruzamento de normatividades se dá de maneira harmônica e equilibrada, ou se o que acontece é o contato de forma desordenada que sobrepõe uma normatividade à outra. Veja-se que as normas técnicas e de gestão como já foi referido deslocam-se da esfera privada e perpassam os limites da estatalidade, possibilitando a criação de novos marcos regulatórios inseridos no próprio Estado.

Essa virada ocorre, principalmente, pela troca da solidariedade pela concorrência enquanto princípio reitor da ação empresarial e estatal, seja no nível nacional ou internacional, colocando-se uma nova forma de governar e movimentar-se na arena "imperial". Como bem referem Dardot e Laval (2016), o capitalismo financeiro tipicamente "imperial" se organiza sobre novas bases em que a competitividade e a concorrência são as molas mestras do político, do social e do jurídico, para além do ambiente da iniciativa privada. Há um princípio de desregulamentação que, em verdade, é extremamente normativo e regula as atividades públicas e privadas a partir dessa virada econômico-neoliberal.

É possível formular, a partir das ideias de Dardot e Laval (2016), que as normas técnicas e de gestão atuam de forma disciplinadora da conduta humana rumo à obtenção de performance condicionada à avaliação técnica e gerencial de sua eficiência. Gera-se uma condição indissociável entre obedecer normas técnicas e de gestão para alcançar os fins buscados seja pela empresa, seja pelo Estado. “A representação cifrada do mundo que governa, atualmente, a gestão dos negócios públicos e privados engloba as organizações internacionais, os Estados e as empresas em um autismo da quantificação que os afasta cada vez mais da realidade da vida dos povos”. (SUPIOT, 2014, p. 77).

Pode-se dizer que "o direito privado se politiza e se publiciza e o direito público se privatiza, a partir da existência de normas com caráter e abrangência públicos, porém produzidos por atores privados em uma modalidade de deslocalização normativa”. (SALDANHA; MELLO; LIMBERGER, 2016, p. 337-354). A partir das considerações de Fornasier e Ferreira (2015), é possível inferir que as fronteiras, antes bem demarcadas entre a hard law - Constituição, normatividade jurídica, etc - e soft law - standards, indicadores, normas de gestão, etc - é cada vez mais porosa e confusa, pois com o aumento da complexidade gerado pelo fenômeno da globalização, inadvertidamente multiplicam-se ordens jurídicas diversas que transitam entre soft law e hard law, bem como cada vez mais os modelos de soft law tornam-se hard law "imperiais", sendo muito mais impositivas do que a normatividade constitucional emanada do Estado.

Efetiva e eficientemente a normatividade "imperial" que em seu cerne é principalmente normatividade empresarial passa a comandar pela via da concorrência de normatividades ${ }^{6}$ a

\footnotetext{
6 É importante deixar claro nesse momento o que se quer determinar/conceituar por concorrência de normatividades ou concorrência normativa. Para tanto, se utiliza a lição de Benoit Frydman: "Os termos "concorrência normativa" ou "concorrência regulatória" (em inglês regulatory competition) geralmente se referem à competição em que se envolvem os estados, global ou regionalmente, ou mesmo entre os entes federativos dentro do próprio Estado, para tornar sua lei mais favorável do que a de outros a todos ou a certos assuntos de direito, bens ou operações que os Estados desejam atrair para seu território ou sob sua jurisdição". (FRYDMAN, 2016, p. 1-19. Tradução livre do autor: "Les termes «concurrence normative» ou «concurrence réglementaire» (en anglais «regulatory competition») désignent le plus souvent la compétition à laquelle se livrent les Etats, au niveau global ou régional, ou même à l'intérieur d'un cadre étatique fédéral, pour rendre leur droit plus favorable que celui des autres à tous ou certains sujets de droit, biens ou opérations que les Etats souhaitent attirer sur leur territoire ou sous leur juridiction".
} 
interação normativa entre normas estatais-constitucionais e normas técnicas e de gestão, como também a sistemática de produção e aplicação das normas jurídicas, mesmo que no âmbito do ente estatal. Essa nova normatividade como se nota, está claramente ligada aos atores privados, em especial ás empresas transnacionais.

Nesse passo, apresenta-se como atores privados, principalmente as empresas transnacionais e as grandes corporações que estendem suas estruturas e práticas por todo o globo terrestre sem obedecer qualquer tipo de fronteira, seja territorial ou jurídica. Budó (2019) ensina tratar-se de um modelo de organização empresarial que tem nas suas práticas a sistemática violação de normas jurídicas/constitucionais e dos direitos humanos, pois, tem em seu cerne a negação a qualquer tipo de prestação de contas, não se submetendo a qualquer regime jurídico, seja nacional ou internacional.

Ainda de acordo com a autora, inevitavelmente para além do poder econômico disponível à essas empresas transnacionais, elas são capacitadas de um grande poder político, pois, no mais das vezes, os seus interesses se confundem com os dos Estados, bem como ocorre uma interdependência que liga diretamente práticas estatais da esfera da política às práticas econômicas dessas empresas e grandes corporações globais. Tais relações, sejam de parceria, sejam de pressão, e até mesmo pela via da corrupção, se dão pela utilização de lobby junto aos parlamentos, pela concessão de financiamento de campanha, pela promessa de geração de empregos, entre outras práticas costumeiras relacionadas às empresas transnacionais. (BUDÓ, 2019).

Nessa linha, é possível afirmar que os interesses dos Estados e dessas grandes corporações, no mais das vezes, confundem-se e imbricam-se, pois, ambos atores acabam por competir no mercado global. Dessa maneira, os Estados passam a sujeitar-se ao regime das normas técnicas e de gestão, por ser o único compatível com a estruturação, funcionamento e movimentação do mercado global, passando a transportar suas prerrogativas para mecanismos internacionais de padronização normativa. Frydman (2018), quando aborda a experiência europeia, é bastante claro ao dizer que cada vez mais há uma transferência completa de competência da normatividade jurídica, estatalconstitucional para o âmbito internacional das normas técnicas europeias e globais. Na prática europeia não há mais sequer uma reserva de atuação para os Estados em matérias como meio ambiente, saúde, segurança, entre outras. Dessa forma, toda a normatividade está sob a perspectiva de harmonização e padronização técnica e de gestão europeias e/ou globais.

Contudo, as normas técnicas adotadas no quadro da nova abordagem (ou fora dela) escapam a qualquer controle de validade jurídica e não podem ser objeto de recurso de anulação perante a Corte de Justiça da União nem de recurso por particulares, donde se estima que não há interesse em contestá-los. (FRYDMAN, 2018, p. 60).

Veja-se que é por demais evidente que se está a falar de uma normatividade que se constitui e atua ao arrepio do Estado, mas, sobretudo, do Direito construído legislativa e democraticamente, do constitucionalismo e dos direitos humanos. Não há preocupação com qualquer validação dessas 
novas normatividades pelos pressupostos tipicamente estatais-constitucionais de concretizar e garantir direitos que propiciem o bem comum.

Sob o ponto de vista concorrencial e não do diálogo, as normas jurídicas soçobram frente às normas empresariais que passam e governar o modo de ação de empresas, organizações internacionais, Estados, governos, etc, e condicionam a atuação de todos esses atores aos fins apontados pelo mercado como instituição "imperial” basilar. De acordo com Frydman (2016, p. 1-19)7, "a implementação da concorrência dos estados e seus direitos funciona como uma técnica alternativa para harmonização de direitos e promove a disseminação de um único modelo normativo".

Esse modelo normativo é o que se denomina no presente trabalho de normatividade "imperial", é um modelo hibrido que unifica as normas técnicas e de gestão com as normas jurídicas com uma sobreposição das primeiras ante as segundas, atendendo aos interesses do mercado e à lógica competitiva e concorrencial das empresas privadas. Para além de competir no mercado, as empresas privadas na atualidade geram uma concorrência normativa entre os Estados, que buscam na esfera internacional atender aos interesses das empresas transnacionais na busca por investimentos, geração de empregos, popularidade para o governo, etc.

Porquanto, a prática de guiar-se por standards e indicadores torna-se uma prática global no mercado normativo apregoado pela concorrência entre as diversas ordens normativas estatais. Cada vez mais cresce a presença do que Frydman (2014) denomina por Objetos Normativos Não Identificados (O.N.N.I) - do original em inglês Unidentified Normative Objects (UNOs), normas que se apresentam de lugares diversos de produção normativa, bem como são aplicadas por diferentes e novos centros de poder, e que proporcionam uma fragmentação da normatividade jurídica que não mais está necessariamente vinculada ao Estado, necessitando de um método pragmático ${ }^{8}$ de análise.

Para o autor, a discussão a respeito de uma ordem normativa global não pode ser colocada de maneira simplista entre a existência (surgimento) ou não de um Estado mundial, que sabemos não existir, e a existência de estruturas (instituições) de governança global, das quais emanam a normatividade global atual. A “observação empírica ensina-nos que as normas não são necessariamente produzidas pelas estruturas de estado ou de governança”[...] (FRYDMAN, 2014, p. 1-17), transbordando os limites tanto da estatalidade quanto das organizações internacionais

7 Tradução livre do autor: "La mise en concurrence des Etats et de leurs droits fonctionne comme une technique alternative à l'harmonisation des droits et favorise la diffusion d'un modèle normatif unique".

8 É importante aqui, caracterizar esse método pragmático: "De acordo com o método pragmático, normas legais são estudadas e interpretadas, menos em consideração à sua origem (as fontes da lei) ou aos relacionamentos lógicos ou hierárquicos que elas mantêm entre elas (a ordem ou o sistema jurídico) do que em relação dos efeitos que elas produzem ou provavelmente produzirão no contexto de suas aplicações. A preocupação com a eficiência é crucial para se estudar devidamente o impacto das regras e instituições e suas mudanças no que tange à indivíduos e grupos, ao gozo de direitos e a alocação de recursos". (FRYDMAN, 2016, p. 1-19). Tradução livre do autor: "Selon la méthode pragmatique, les normes juridiques sont étudiées et interprétées, moins en considération de leur origine (les sources du droit) ou des relations, logiques ou hiérarchiques, qu'elles entretiennent entre elles (l'ordre ou le système juridique) que des effets qu'elles produisent ou sont susceptibles de produire dans les contextes de leurs applications. Le souci de l'effectivité est déterminant de même que l'étude de l'impact des règles et des institutions et de leurs modifications sur les individus et les groupes, la jouissance des droits et l'allocation des ressources". 
(intergovernamentais) que constituem o aparato de governança global na atualidade ${ }^{9}$. Com efeito:

Não se pode ignorar, especialmente, que o aumento dos poderes dos atores não estatais que interferem na economia e na vida política dos Estados tem promovido, ao longo de décadas, a necessidade de redesenhar a governança mundial em termos de direitos, deveres e responsabilidades. (SALDANHA, 2018, p. 207231).

Desse modo, a ordem normativa global não pode ser pensada como uma ordem normativa única ao modo das ordens normativas estatais, deve-se ter clara a existência de sistemas legais interrelacionados advindos de diversas normatividades e atores, independentemente de fazer parte ou não de uma dada ordem jurídica como a conhecemos desde a modernidade. (FRYDMAN, 2014). Porém, essa opção feita por Benoit Frydman nos parece bastante perigosa, ao somente assumir a pluralidade de normas independentemente dos atores, lugares de produção e aplicação e natureza dessas normas, acreditando em um pluralismo normativo ordenado em matéria global. Frydman (2014), em certa medida, aponta um meio termo ao dizer no mesmo artigo que ao admitir essa pluralidade de normas, sem importar necessariamente de qual centro de poder advém essa norma - ou seja, se de atores privados, estatais, paraestatais, bem como se normas jurídicas, normas técnicas ou de gestão - apenas está abandonando um formalismo que não é benéfico para a análise e compreensão da conjuntura atual.

Mesmo com essa advertência do autor, entende-se no presente artigo que é muito perigoso adotar essa postura de relativização da importância do lugar do qual decorre determinada normatividade, determinadas normas. Não se quer, no presente artigo, negar o surgimento de novos atores no universo da produção e aplicação das normas; no entanto, não se pode naturalizar tal processo ao nível de uma naturalização própria das normatividades privadas sobre a normatividade estatal, nem das normas técnicas e de gestão sobre as normas jurídico-constitucionais, pois as primeiras operam em uma zona eminentemente privada, sem ligação qualquer com os fins a serem alcançados pela sociedade, pelos sujeitos de direito.

Veja-se que a relação entre capitalismo neoliberal e a ação de atores privados, no que tange a práticas que atentam contra os sistemas jurídicos e os direitos humanos, é visível e latente, o que mostra as armas utilizadas pelo "Império" na consecução de seus fins. Nota-se uma típica ação "imperial" no entrelaçamento entre Estados e mercado em direção aos fins econômicos que aparentemente beneficiarão às duas instituições, mas que em verdade trazem ganhos apenas para os atores privados envolvidos nessa relação, e para a própria estrutura "imperial" que cada vez mais se agiganta enquanto uma forma central de biopoder.

Dessa forma, mesmo que a normatividade "imperial" se produza a partir de um biopoder central forte e denso, os atores privados atuam com liberdade e facilidade por suas estruturas seja de produção quanto de aplicação das normas. É evidente que as normas técnicas e de gestão nascem sobretudo da esfera privada e de atores que habitam o ambiente "imperial", bem como

9 Tradução livre do autor: "Empirical observation teaches us that norms are not necessarily produced by the structures of inter-state or para-state governance". 
o ambiente estatal, mas que atuam para além das normas estatais e constitucionais, tendo como prática costumeira o descumprimento do Direito e a violação dos direitos humanos.

Assim, as variadas normatividades que se colocam no espaço-tempo "imperial" passam, necessariamente, a relacionar-se e a criar vínculos no que tange à sua produção e aplicação, bem como surgem de variados atores que buscam a defesa de seus interesses específicos. No entanto, o que deve ser questionado é como se dá essa relação, e qual o papel que passam a ter os direitos humanos em meio a um ambiente "imperial" em que os atores privados optam, no mais das vezes, pela violação sistemática do Direito, da Constituição, e dos direitos humanos.

Desse modo, se torna importante compreender a ação das empresas transnacionais nesse novo paradigma de soberania, desvelando as suas práticas orquestradas e sistemáticas de violação dos direitos humanos, e como se pode chegar à responsabilização dessas grandes corporações no âmbito nacional e internacional. Nessa lógica de desresponsabilização e impunidade, uma das práticas mais utilizadas pelas empresas transnacionais na violação a sistemas jurídicos e aos direitos humanos é o law shopping, sendo necessário desvelar como o Direito e os direitos humanos podem ser barreiras a essa prática. É o que se passa a discutir.

\section{ASEMPRESASTRANSCACIONAISEAPRÁTICADOLAWSHOPPING: ESCOLHENDO NORMATIVIDADES E VIOLANDO DIREITOS}

Seguindo caminho, as empresas transnacionais se mostram como um dos principais atores inseridos no paradigma "imperial" de soberania, constituindo-se, para além de um novo ator no mercado, um novo ator político e jurídico de grande poder no âmbito nacional e internacional. Nesse passo, além de ser um novo ator no que tange à produção e aplicação de normas jurídicas e, sobretudo, não jurídicas, as grandes corporações globais se tornam importantíssimas na definição da normatividade estatal, ou seja, das normas jurídicas, constitucionais, de modo a construir ordenamentos jurídicos mais favoráveis às suas práticas violadoras de direitos - dos direitos humanos.

Torna-se cada vez mais comum que os Estados adequem a sua ordem jurídica interna aos interesses das empresas transnacionais, sempre no sentido desregulatório, bem como assentado nas práticas internacionais de padronização normativa a partir do uso de normas técnicas, de gestão e de indicadores e standards normativos consubstanciados por organizações internacionais, nos rumos apontados pelo mercado e pelo "Império". Nesse contexto, as ordens jurídicas estatais cada vez mais se mostram fragilizadas e à serviço do mercado e do "Império", pois devem inserir-se na lógica da competitividade (concorrência) mercadológica, econômica, criando também práticas de concorrência normativa, quer-se dizer, entre ordenamentos jurídicos.

Nesse sentido, se dá a manifestação do que se denomina de law shopping, que é nada mais do que a aplicação do princípio da concorrência ao Direito, ao invés de o Direito reger a (livre) concorrência entre mercados e empresas. Por essa prática do law shopping as empresas 
literalmente em meio a um mercado de ordens normativas e/ou sistemas jurídicos escolhem os que tem normas jurídicas mais favoráveis ao desenvolvimento de suas atividades empresariais. Nesse sentido, se pode tratar de normas fiscais mais benéficas, de normas trabalhistas menos rígidas, questões relativas à responsabilização civil e penal das empresas no que tange a questões ambientais, de acidentes, práticas monopolistas, etc.

A ação das empresas transnacionais implica uma modificação na própria teoria do direito, na medida em que se descentra a produção normativa das mãos do Estado, passando a ter uma multiplicidade de atores envoltos em um modelo interativo e descentralizado de produção normativa, o que acaba por gerar uma proliferação de normas. (SALDANHA, 2018). Pode-se dizer que há uma nova gramática jurídica, pontuada pela multiplicação de centros de produção normativa, bem como por uma pluralidade de normas. Impõe-se ao arrepio do Estado, ou, através desse, novas normas trabalhistas, novas normas no que diz respeito à produção de bens e serviços, no que tange a políticas tributárias, entre outras questões. De acordo com Frydman (2014, p. 8):

A globalização coloca os atores transnacionais em uma nova situação. Eles não são mais sujeitos de um sistema legal predeterminado, sujeitos às restrições e, se necessário, as sanções deste sistema. Em vez disso, eles são colocados diante de uma paisagem fragmentada, um mosaico de sistemas legais, que corresponde aproximadamente ao mapa político do mundo, dividido em Estados. ${ }^{10}$

Com base nas liberdades estritamente mercadológicas (liberdade de estabelecimento, de circulação de capitais e mercadorias, etc), as empresas transnacionais consolidam uma prática de não se submeterem às normas jurídicas dos Estados nos quais operam, escolhendo um Estado e, consequentemente, um ordenamento jurídico mais vantajoso para as suas atividades, fazendo com que o Direito em si se torne também um negócio. (SUPIOT, 2014). O "Império", pela via do mercado, impõe uma liberdade que não se liga a questões mercadológicas, mas sim à substancialidade jurídica, à vinculatividade dos direitos humanos, pois concebe um conceito de "liberdade normativa"; em verdade, uma liberalidade que age sobre o Direito e o insere na sistemática concorrencial que se espalha por todas as esferas da sociedade.

Se a agenda global exige a constituição de um espaço-tempo financeiro baseado economicamente na técnica, e consegue desenvolvê-lo a partir da adoção da nova normatividade “imperial” com suas normas técnicas e de gestão, indicadores e standards, ela acaba também por desconstituir a normatividade jurídica estatal, justamente com a utilização dessa nova normatividade no interior do Estado. Assim como são rompidas as fronteiras nacionais do ponto de vista geográfico, as fronteiras jurídico-normativas são desfeitas, deslocadas, movimentadas, de acordo com os movimentos das empresas transnacionais. (SUPIOT, 2014). De acordo com Kashiura Júnior (2019), essa transposição da normatividade jurídico-estatal para a normatividade numérico-"imperial" ocorre com a privatização do Estado, ou seja, com a troca do modelo de gestão 10 Tradução livre do autor: "Globalization places transnational actors in a new situation. They are no longer subjects of a predetermined legal system, subjected to the constraints and if need be the sanctions of this system. Rather, they are placed before a fragmented landscape, a mosaic of legal systems, that roughly corresponds to the political map of the world, divided into States." 
pública para um modelo de gestão privada que é o adotado pelas grandes empresas transnacionais. A questão, aqui, é que se pelo viés da eficiência vê-se - ou se pode ver - com bons olhos essa transposição, o grande componente do conceito de eficiência empregado por essas grandes corporações é a geração de lucro, e isso vai totalmente de encontro à lógica estatal, que, embora deva se preocupar com as receitas, evidentemente não deve se preocupar com lucratividade, mas sim, com o atendimento dos direitos humanos.

Na Europa, o próprio Tribunal de Justiça das Comunidades Europeias adota a postura que confere às empresas transnacionais o poder de evitar as normas jurídicas menos benéficas do Estado no qual ela exerce as suas atividades, podendo registrar-se em outro Estado no qual as normas jurídicas sejam mais benéficas, permissivas. Verdadeiramente, apontase para a construção de um mercado de normatividades à disposição das empresas transnacionais para escolherem a ordem jurídica que lhes for mais benéfica e menos agressiva do ponto de vista normativo. (SUPIOT, 2014).

Nessa maré, o que Supiot (2014) chama de "darwinismo jurídico" implica na hibridação entre sistemas jurídicos de civil law e de common law, adaptando-se os primeiros aos segundos por uma maior atração dos mecanismos jurídicos da common law para as empresas transnacionais ${ }^{11}$. Os sistemas jurídicos mundiais dão ordem à uma corrida rumo a normas mais atrativas para as grandes empresas transnacionais, o que gera uma verdadeira composição normativa híbrida, que une normas mais benéficas de determinados ordenamentos jurídicos de outros países, ou, então, estabelece em situações específicas para aquelas empresas específicas a possibilidade de uma norma jurídica diferenciada, ou, aplicável diferenciadamente.

Essa perspectiva de atuação dos Estados e das corporações transnacionais pode ser notada a partir de uma análise do Acordo Sobre Comércio e Serviços (TISA, na sigla em inglês). Com a análise desse acordo, fica clara a ordenação neoliberal na mesma na linha da concorrência e de desregulação do mercado - que, como já referido, é tão normativa quanto as formas de regulação clássicas - começando a sua negociação no ano de 2012 e contando na atualidade com a participação de 23 países-membros da Organização Mundial do Comércio (OMC) e com países da União Europeia. (SALDANHA; MELLO; LIMBERGER, 2016).

Oficialmente, justifica-se tal acordo pela necessidade da abertura do comércio de serviços em larga escala no munda/economia globalizado, pois, economicamente, o setor dos serviços possui papel importante para a economia e o desenvolvimento dos países, bem como para a garantia de bem-estar às populações. $\mathrm{O}$ acordo em tela abarca todos os tipos de serviços à exceção dos que devem ser prestados exclusivamente pelo Estado, como é o caso do sistema de

11 De acordo com Ugo Mattei o direito norte-americano, estruturalmente está organizado de modo que o poder político direto seja contrabalançado por um procedimento de dupla verificação feita por profissionais que não estão ligados ao sistema político ou jurídico. Para o autor também o auto grau de descentralização do sistema jurídico norte-americano determina uma adaptação mais fácil da prática jurídica nacional às práticas jurídicas globais de escolha do sistema jurídico e da jurisdição mais favorável. A escolha da norma jurídica e da jurisdição mais benéfica à empresa são algo que estão na ordem do dia no Direito estadunidense. (MATTEI, 2003). Ademais o sistema jurídico estadunidense, bem como, o sistema político-administrativo está habituado a operar a partir das disposições retiradas de standards e indicadores de práticas de boa governança, que no mais das vezes serve de guia para a construção da sua normatividade. 
justiça. Para além dos serviços a serem regulados, é importante deixar claro que a real intenção ao acordo é constituir uma zona desregulamentada no que tange aos serviços, gerando uma onda de privatizações na prestação de serviços que hoje estão sob os cuidados do Estado. (SALDANHA; MELLO; LIBERGER, 2016). Com efeito:

Dentre os muitos perigos desse acordo, o principal deles é a sua realização longe de qualquer cariz democrático. As tratativas vêm sendo realizadas a portas fechadas entre os Estados e sob o lobby das empresas, de modo que o conhecimento que se tem sobre esse hoje é por meio de informações oficiais esparsas, relatórios que abordam pontos polêmicos sobre temas que já foram divulgados ou por vazamentos que ocorreram por meio do Wikileaks. (SALDANHA; MELLO; LIBERGER, 2016, p. 337-354). ${ }^{12}$

Certamente, o que se vivencia é um estado de coisas que está profundamente vinculado às ordenações neoliberais em direção à lógica do mercado como nova "razão do mundo". A racionalidade que permeia essa normatividade encarnada no Acordo Sobre Comércio e Serviços (TISA) não é mais a racionalidade afeita à normatividade estatal, que legislativa e, democraticamente, mesmo que com problemas, busca a garantia e concretização dos direitos humanos estendidos aos sujeitos nacional e internacionalmente. A racionalidade que produz tal acordo é a da razão concorrencial típica do neoliberalismo e que biopoliticamente passa a comandar todos os espaços da vida em sociedade.

Sob essa perspectiva, a prática do law shopping se torna a regra, pois as ordens jurídicas estatais ficam extremamente fragilizadas perante as empresas transnacionais. Por não haver uma normatividade que regule as relações entre as empresas transnacionais e os Estados sob um prisma internacional, as empresas transnacionais acabam por conseguir burlar os sistemas jurídicos nacionais, utilizando-se do law shopping e construindo uma cadeia produtiva a partir de empresas terceirizadas localizadas em países em que as normas jurídicas relativas à proteção do trabalhador, as normas tributárias, ou sobre bens e serviços são mais brandas. (MATOS; MATIAS, 2018).

A fim de ajudar os "consumidores de Direito" a fazerem sua escolha neste "mercado de normas", o Banco Mundial publica todos os anos, desde 2004, no âmbito de seu programa Going Business, um relatório avaliando os direitos nacionais, tendo por referência a eficácia econômica. A base de dados cifrados assim mostrados é destinada a fornecer as "medidas objetivas" do Direito de cento e setenta e oito países (rebatizados como "economias"). Ela contém, essencialmente, indicadores estatísticos da "inflexibilidade" dos direitos trabalhistas desses países [...]. O quadro comparativo de todos os Direitos do Trabalho do mundo é construído ao redor dos seguintes indicadores: dificuldade de emprego; dificuldade de

\footnotetext{
12 Veja-se que as condições que circundam a construção do tratado são de total e constante vilipendio à força política Estado e à normatividade do constitucionalismo. Para tal, pode-se descrever três cláusulas nas quais centra-se o acordo, como o trinque-te, prevendo que um Estado não pode reintroduzir um obstáculo já eliminado ao comércio, tornando a desregulamentação permanente. Outra cláusula é a de manutenção do status quo, pela qual se o governo de determinado Estado privatizar um serviço, tal serviço não poderá mais ser estatizado, impedindo o Estado de retroceder na sua decisão inicial. A terceira cláusula é o regime de top down que vai além de impossibilitar a reestatização, impondo verticalmente a utilização de mecanismos que obrigam os Estados a submeter ao TISA a maior quantidade possível de serviços. (SALDANHA; MELLO; LIBERGER, 2016, p. 337-354).
} 
prolongamento ou de redução da duração do trabalho; dificuldade econômica de demissão de um trabalhador; índice de inflexibilidade do emprego; custos de um emprego e custos de uma demissão. Compreende-se que "dificuldades" e "inflexibilidades" qualificam as regras e "custos" dos direitos protetores dos assalariados. O índice de "inflexibilidade do emprego" impõe, assim, pontos de penalidade aos Estados que admitem um excesso de direitos aos trabalhadores [...]. (SUPIOT, 2014, p. 59-60).

Tal situação, no que tange às leis trabalhistas, mostra-se com muita clareza na prática adotadas por inúmeras empresas transnacionais da área do vestuário. A indústria do vestuário é uma das mais reconhecidas por adotar práticas atentatórias contra os direitos humanos relativos aos trabalhadores. A adoção do que se chama mundialmente de empresas fastfashion é um método reconhecido pelo descumprimento de direitos dos trabalhadores, por tratar-se de uma produção em larga escala e baixo custo que atinge necessariamente todas as etapas produtivas, incluindo os gastos com a mão de obra. Marcas que são conhecidas por utilizar-se de tal metodologia são a Zara, a H\&M, a Forever 21, a Gap, dentre outras. (MATOS; MATIAS, 2018).

"A busca por trabalhadores em países asiáticos e latino-americanos reflete a procura por mão de obra barata, sem proteção ou fiscalização adequada do Estado" (MATOS; MATIAS, 2018, p. 259), o que demostra que "a fragilidade política e econômica de muitos Estados, ao longo do tempo, tem sido um fator recorrente e estimulador das ações nocivas dessas empresas especialmente pela timidez ou até mesmo inexistência de imposição de responsabilidades". (SALDANHA, 2018, p. 210). Perceba-se que é justamente o que conforma a prática do law shopping: a opção por Estados nos quais os seus ordenamentos jurídicos, ou seja, as normas jurídico-constitucionais emanadas do Estado, ofereçam os menores entraves possíveis à atuação econômico-produtiva das empresas transnacionais, não importando se isso produz custos aos direitos humanos, pois somente não pode significar custos elevados à atuação da empresa. Com efeito:

Essas empresas tendem a dar prioridade, até certo ponto, ao Estado que possui o menor número de requisitos e os requisitos mais facilitados. Os deveres legais, no sentido mais amplo e obviamente incluindo a previdência social, obrigações fiscais e restrições ambientais, são percebidas como custos que devem ser minimizados na busca incessante da maximização do lucro. Conhecemos muito bem essa situação com a questão da "terceirização". Essa situação competitiva leva a uma "guerra de preços" normativa, uma guerra que é ainda mais acirrada, pois a diferença entre os níveis regulatórios dos sistemas jurídicos que competem no planeta é enorme[...]. (FRYDMAN, 2014, p. 9). ${ }^{13}$

Nesse contexto, o Direito não opera mais como balizador da atuação do mercado a partir da constituição de um arcabouço normativo que imponha limites e deveres na atuação econômica. 13 Tradução livre do autor: "Those firms tend to give priority, up to a certain point, to the State that has the lowest requirements. The legal duties, in the largest sense and obviously including social security, fiscal obligations and environmental constraints, are perceived as costs that are to be minimised in the unrelenting pursuit of profit maximisation. We know this situation very well through the issue of "outsourcing". This competitive situation leads to a normative "price war", a war which is all the fiercer as the difference between the regulatory levels of legal systems competing on the planet is huge[...]". 
O Direito acaba se sujeitando à produção de uma outra normatividade que se constrói ao arrepio da estatalidade e nas instituições democráticas, bem como quando legisla, quando atua como produtor das normas - pelo menos as tipicamente jurídicas - acaba sendo conduzido pelos indicadores e standards internacionais que se colocam como nova normatividade no âmbito das normas técnicas e de gestão que atuam sobre a estrutura e o funcionamento do Estado. De acordo com Kashiura Júnior (2019), essa movimentação em direção de uma outra normatividade faz com o que os deveres de solidariedade típicos do Estado Social (e Democrático de Direito) soçobrem frente à ordem econômica neoliberal e à atuação das empresas transnacionais, sofrendo os principais ataques os direitos trabalhistas, o direito tributário e a seguridade social pois, de acordo com os indicadores, tais direitos reduzem a eficiência econômica das empresas transnacionais.

Dessa forma, o que se vislumbra é que a normatividade "imperial" exerce um poder regulatório silencioso, pois esconde-se atrás de um aparente movimento desregulatório que implicaria a ausência de normas, para em verdade impor uma normatividade que silenciosamente governa a tudo e a todos. Nas trilhas do "Império", o exercício normativo é um exercício do biopoder que se coloca como centro de poder e estende a sua normatividade a-normativa por sobre todo o globo terrestre. Fala-se a-normativa pois é uma normatividade que nega a sua normatividade, mas, no entanto, de maneira incisiva governa as ações dos atores privados e dos entes públicos, obrigando os Estados a seguirem os rumos traçados pelo "Império".

Esse rumo, no que tange ao Direito, é o caminho para um espaço-tempo de concorrência generalizada entre Estados, ordenamentos normativos, sistemas jurídicos, sistemas processuais, e, também, uma concorrência entre práticas estatais no sentido de beneficiar as corporações transnacionais, fazendo com que as mesmas se instalem em seus países e violem os seus direitos. A garantia dos direitos, tipicamente função estatal, torna-se garantia dos números, ou seja, o Estado está ancorado em uma lógica de normalização de condutas e consentimento intransigente para com os interesses privados. O "Império" obriga regulatoriamente a desregulação; obriga, a partir do exercício do biopoder, que uma outra normatividade surja e se sobreponha ao Direito e aos Direitos Humanos.

Desde essa perspectiva, o cenário é de total e descontrolada desregulação em nome de uma regulação descentralizada e orientada por novos princípios e por uma nova razão. A razão neoliberal das empresas transnacionais e o princípio da concorrência ordenam a normatividade "imperial" e provocam não só o tensionamento, mas sim a ruptura para com a normatividade estatal, ou seja, com o Direito, com o constitucionalismo e com os direitos humanos. O uso das normas técnicas e de gestão, via indicadores e standards, geram um descompasso entre pensar empresarialmente e pensar juridicamente a normatividade, fazendo com que a primeira se sobreponha à segunda e crie um mercado de normatividades que devem se adaptar cada vez mais, e mais rapidamente, à normatividade "imperial" (empresarial).

Evidentemente, não se pretende com o presente trabalho negar o quadro pintado globalmente por esse novo paradigma "imperial" de soberania, um quadro que tem as cores da concorrência normativa, da multiplicidade de atores e de centros de produção e aplicação das 
normas e, principalmente, de pluralidade de normas e de ordens normativas, para além das produzidas pelos Estados. Porquanto, o que se defende nesse artigo é que à concorrência deve-se antepor o diálogo de normatividades, e que esse diálogo não pode se dar ao arrepio das instituições democráticas, nem afastado da sociedade civil, e muito menos sem levar em conta os direitos humanos, seja sob um prisma nacional ou internacional de garantia e concretização.

É necessário que a Constituição ainda constitua, e que o constitucionalismo se coloque como uma trincheira - se não a última trincheira - de resistência frente à ação do "Império" através do mercado e das empresas transnacionais. A normatividade estatal deve dialogar com as novas normatividades oriundas da esfera privada e materializadas em normas técnicas e de gestão, mas jamais deve se curvar à essas novas normatividades, sendo necessário resistir à privatização do espaço público, e, nesse sentido, sobretudo do Direito. Sob essa perspectiva, quando essas novas normatividades se referirem a questões relativas ao bem-estar dos cidadãos - e aqui o termo cidadão não tem o condão de se referir somente ao cidadão de determinado Estado, mas sim, a todo e qualquer cidadão, a todo e qualquer ser humano - a construção dessas normas deve estar aberta ao debate democrático face às instituições estatais e à sociedade civil, expostas à aprovação dos que serão diretamente atingidos por essa nova normatividade.

Nesse sentido, jamais pode ser permitido que uma empresa transnacional ao se utilizar da prerrogativa de escolha que lhe cabe pela falta de uma regulamentação condizente no que tange aos direitos humanos e empresas, possa escolher uma norma ou uma ordem normativa mais benéfica para si, mas que viole os direitos humanos. Obviamente, também não pode possibilitar às empresas transnacionais a escolha de Estados débeis política e economicamente para violar direitos humanos, isso a partir da construção de um tratado internacional sobre direitos humanos e empresas (transnacionais), da mesma forma que não se pode permitir que a terceirização das funções produtivas exima as empresas transnacionais de responsabilidade em relação à violação de direitos.

Desse modo, por mais que a multiplicidade de centros de produção e aplicação normativa, bem como a pluralidade de normas, crie condições e permita a prática do law shopping, o mercado normativo estará limitado por normas nacionais e internacionais de proteção, garantia e concretização dos direitos humanos, como também à ordem constitucional de cada país. Colocando parâmetros a partir dos direitos humanos e do constitucionalismo à prática do law shopping, necessariamente caminha-se para uma prática de diálogo entre as diversas normatividades e não de sobreposição da normatividade "imperial" sobre a normatividade estatal.

Assim, o respeito à Constituição e aos direitos humanos não deve soçobrar frente às novas ordens normativas, e frente à concorrência jurídico-normativa imposta aos Estados na contemporaneidade, e frente a práticas como a law shopping, que tem o intuito único de violar direitos em nome da eficiência numérica do lucro. O constitucionalismo e os direitos humanos ainda têm espaço, e ainda têm função, e cada vez mais essa função se torna importante para resistir ao "Império" e às suas práticas, estruturas e normatividades que vilipendiam os direitos e expõem os excluídos à mais exclusão e expropriação. O constitucionalismo é a última morada 
dos direitos humanos, e o Estado ainda segue sendo o lugar privilegiado de proteção, garantia e concretização desses direitos face à ação "imperial".

\section{CONSIDERAÇÕES FINAIS}

Chegando-se ao fim do presente trabalho, é possível concluir que as instituições jurídicopolíticas modernas, centrando-se a análise no Estado e no constitucionalismo que com ele se relaciona, perdem o seu espaço e a sua centralidade para novos atores globais, para novas normatividades, e, principalmente para um novo paradigma de soberania que atende pelo nome de "Império".

O paradigma "imperial" organiza e estrutura uma nova ordem normativa que se constitui a partir da ação de novos atores, principalmente as empresas transnacionais, que criam novas espécies normativas, as normas técnicas e de gestão que concorrem e se sobrepõe à normatividade jurídica. Essas novas normatividades "imperiais" são ordenadas pelo princípio da concorrência e pelo atendimento a necessidades relativas aos atores privados que passam a compor um novo cenário de lugares de produção e aplicação do direito, em que os direitos soçobram face à eficiência mercadológica medida numericamente pelo lucro.

Assim, o cenário atual ganha mecanismos de ação das grandes corporações transnacionais no sentido de burlar e fragilizar os sistemas jurídicos nacionais e internacionais, em que ocupa lugar de destaque a prática do law shopping, em que empresas transnacionais e Estados institucionalizam, estruturam e movimentam um verdadeiro mercado normativo na busca pelas maiores facilidades para a obtenção de lucro. No entanto, se a normatividade estatal se mostra atrativa para as empresas transnacionais, ela se mostra incompatível com o Direito, com a constitucionalidade e com os direitos humanos, e, é por esse motivo que cada vez mais o constitucionalismo ao invés de perder a sua importância e o seu espaço, ganha mais importância frente à ação "imperial” via empresas transnacionais e a construção de normas técnicas e de gestão a partir de standards e indicadores. O constitucionalismo e o Estado-nação tornam-se - ou deveriam se tornar - a última barreira de contenção da ação "imperial”, desempenhando papel vital na manutenção da ordem jurídica, constitucional e na proteção, garantia e concretização dos direitos humanos. Dessa forma, o constitucionalismo é que deve conduzir a relação entre a normatividade constitucional (estatal) e a normatividade "imperial" subvertendo a relação de concorrência em diálogo entre normatividades, e colocando parâmetros e limites há prática do law shopping.

\section{REFERÊNCIAS}

BOLZAN DE MORAIS, Jose Luis (org.). Estado \& constituição: o "fim” do Estado de direito. Florianópolis: Tirant lo Blanch, 2018a. 
BOLZAN DE MORAIS, Jose Luis (org.). O Estado e suas crises. Porto Alegre: Livraria do Advogado, 2005.

BOLZAN DE MORAIS, José Luis. As crises do Estado e da constituição e a transformação espaço-temporal dos direitos humanos. Porto Alegre: Livraria do Advogado, 2011.

BOLZAN DE MORAIS, Jose Luis. O Estado de direito "confrontado" pela "revolução da internet"!. Revista Eletrônica do Curso de Direito da UFSM, Santa Maria, RS, v. 13, n. 3, p. 876-903, dez. 2018b.

BOLZAN DE MORAIS, Jose Luis; HOFFMAM, Fernando. Por uma identidade constitucional “comum”. Revista Novos Estudos Jurídicos, Itajaí, SC, v. 20, n. 3, p. 860-884, set./dez. 2015.

BOLZAN DE MORAIS, Jose Luis; COPETTI NETO, Alfredo (org.). Estado e constituição: a internacionalização do direito a partir dos direitos humanos. Ijuí: Unijuí, 2013.

BOLZAN DE MORAIS, Jose Luis; SALDANHA, Jânia Maria Lopes; VIEIRA, Gustavo Oliveira. O constitucionalismo e a internacionalização dos direitos humanos. In: BOLZAN DE MORAIS, Jose Luis; COPETTI NETO, Alfredo (org.). Estado e constituição: a internacionalização do direito a partir dos direitos humanos. Ijuí: Unijuí, 2013.

BUDÓ, Marília de Nardin. "Um Massacre Silencioso Que Continua": um olhar criminológico sobre os danos sociais causados pelo amianto. Revista Novos Estudos Jurídicos, Itajaí, v. 24, n. 2, p. 483-513, maio/ago. 2019.

DARDOT, Pierre; LAVAL, Cristian. A nova razão do mundo: ensaio sobre a sociedade neoliberal. Tradução de Mariana Echalar. São Paulo: Boitempo, 2016.

FORNASIER, Mateus de Oliveira; FERREIRA, Luciano Vaz. A regulação das empresas transnacionais entre as ordens jurídicas estatais e não estatais. Revista de Direito Intermacional, Brasília, v. 12, n. 1, p. 395-414, 2015.

FRYDMAN, Benoit. A pragmatic approach to global law. Centre Perelman de Philosophie du Droit, Bruxelles, n. 2014/6, p. 1-17, 2014. Working paper. Disponível em: http://www.philodroit. be/IMG/pdf/bf-concurrence-2016-3.pdf. Acesso em: 11 jan. 2020.

FRYDMAN, Benoit. La concurrence normative européenne et globale. Centre Perelman de Philosophie du Droit, Bruxelles, n. 2016/3, p. 1-19, 2016. Working paper. Disponível em: http:// www.philodroit.be/IMG/pdf/bf-concurrence-2016-3.pdf. Acesso em: 11 jan. 2020.

FRYDMAN, Benoit. O fim do Estado de direito: governar por standards e indicadores. Tradução de Mara Beatriz Krug. Porto Alegre: Livraria do Advogado, 2018.

HARDT, Michael; NEGRI, Antonio. Império. Tradução de Berilo Vargas. Rio de Janeiro: Record, 2002.

HOFFMAM, Fernando. Do cosmopolitismo ao "comumpolitismo" enquanto um novo ambiente para os direitos humanos na era do Império. Rio de Janeiro: Lumen Juris, 2019.

KASHIURA JÚNIOR, Celso. Do governo democrático à governança pelos números: apontamentos para uma discussão a partir de Alain Supiot. Revista Em Tempo, Marília, v. 18, p. 
343-363, 2019.

MATOS, Laura Germano; MATIAS, João Luis Nogueira. Multinacionais fast fashion e direitos humanos: em busca de novos padrões de responsabilização. Revista de Direito Internacional, Brasília, v. 15, n. 2, p. 254-268, 2018.

MATTEI, Ugo. A theory of imperial law: a study on U.S. hegemony and the Latin resistance. Indiana Journal of Global Legal Studies, Indiana, v. 10, Is. 1, p. 383-448, 2003. Disponível em: https://www.repository.law.indiana.edu/cgi/viewcontent.cgi?article=1260\& context=ijgls. Acesso em: 11 jan. 2020.

SALDANHA, Jânia Maria Lopes. Do direito soft ao direito hard em matéria de responsabilidade jurídica das empresas transnacionais por violação dos direitos humanos. In: BOLZAN DE MORAIS, Jose Luis (org). Estado \& Constituição: o "fim" do Estado de Direito. Florianópolis: Tirant lo Blanch, 2018. p. 207-231.

SALDANHA, Jânia Maria Lopes; MELLO, Rafaela da Cruz; LIBERGER, Têmis. Do governo por leis à governança por números: breve análise do Trade In Service Agreement (TISA),

Revista de Direito Intermacional, Brasília, v. 13, n. 3, p. 337-354, 2016.

STRECK, Lenio Luiz; BOLZAN DE MORAIS, José Luis. Ciência política e teoria do Estado. Porto Alegre: Livraria do Advogado, 2019.

SUPIOT, Alain. O espírito de Filadélfia: a justiça social diante do mercado total. Tradução de Tânia do Valle Tschiedel. Porto Alegre: Sulina, 2014.

Como citar: HOFFMAM, Fernando. Normatividade imperial, law shopping e empresas transnacionais: como ficam os direitos humanos!?. Scientia luris, Londrina, v. 25, n. 3, p. 25-48, nov. 2021. DOI: 10.5433/21788189.2021v25n3p25. ISSN: 2178-8189.

Recebido em 2020-06-26

Aprovado em 2021-09-26 